Amdahl. HCA Healthcare Journal of Medicine (2022) 3:1.

https://doi.org/10.36518/2689-0216.1434

\title{
Painting
}

\section{Golden Hour}

Christoffer A. Amdahl, MD 1

\section{Abstract}

\section{Description}

Art is a vital part of the human experience. We spend so much time completely immersed in the biological sciences in medicine, which explain how we mechanically operate, looking at various neurological theories and various pharmacological therapies. However, there is not a discrete science that allows for the shared perceptions of emotions as much as the arts. A painting can immerse the viewer in a myriad of different feelings from the artist in a way that language and numbers simply cannot comprehend. The arts are not only important, they are a necessary component of being human that allows us to capture a moment in time of our own existence, one in which we can see our greatest joys or deepest sorrows, and share it with those close to us.

\section{Keywords}

medicine in the arts; humanities; painting; self care

\section{Conflicts of Interest}

The author declares he has no conflicts of interest.

Dr Amdahl is an employee of Medical City Arlington, a hospital affiliated with the journal's publisher.

This research was supported (in whole or in part) by HCA Healthcare and/or an HCA Healthcare affiliated entity. The views expressed in this publication represent those of the author(s) and do not necessarily represent the official views of HCA Healthcare or any of its affiliated entities.

\section{Author Affiliation}

1. Medical City Arlington, Arlington, TX 
HCA Healthcare Journal of Medicine

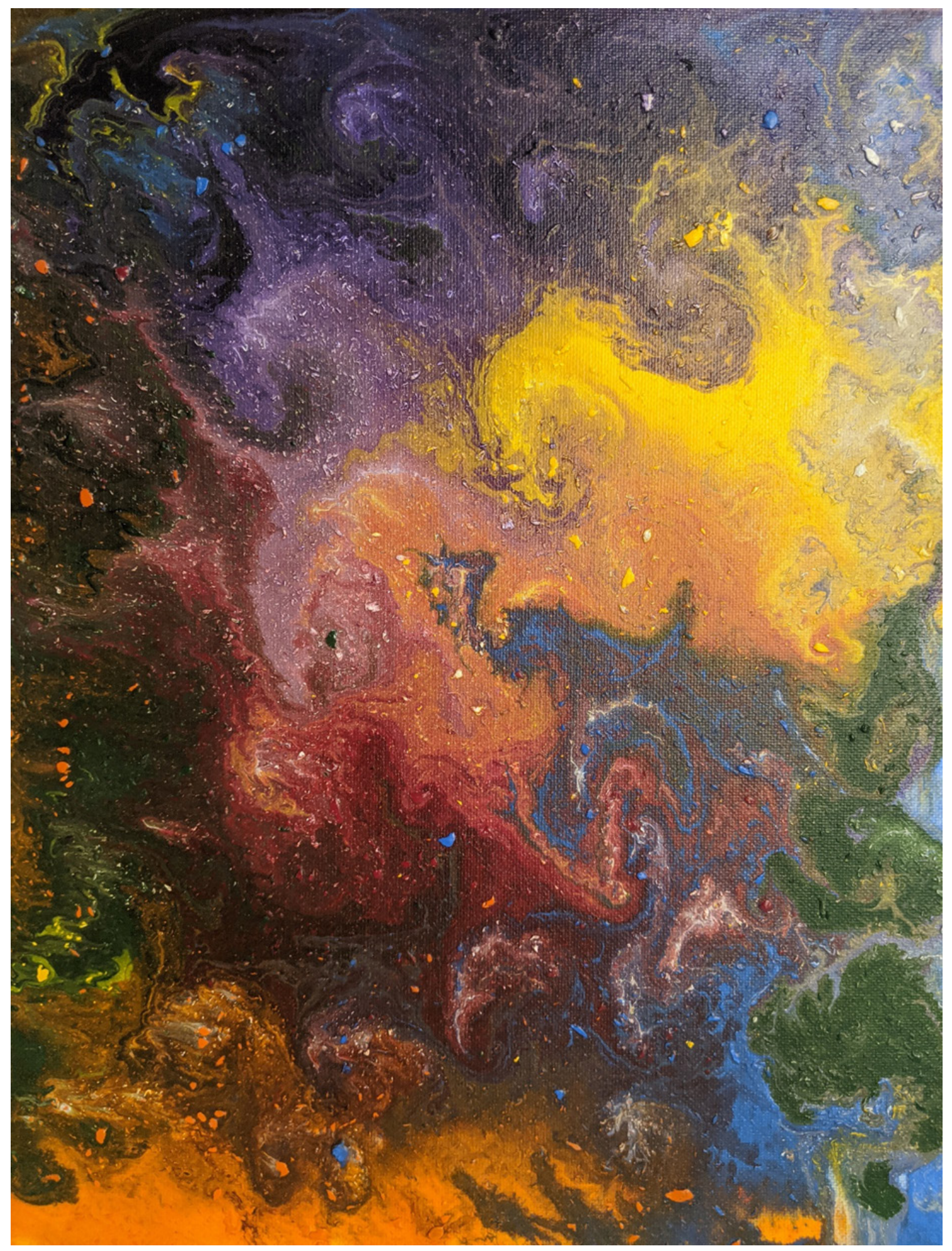

